\title{
Consideration of the transient material behavior under variable amplitude loading in the fatigue assessment of nodular cast iron using the strain-life approach
}

\author{
Jan Hesseler ${ }^{1}$, Jörg Baumgartner ${ }^{1}$, and Christoph Bleicher ${ }^{1}$ \\ ${ }^{1}$ Fraunhofer Institute for Structural Durability and System Reliability LBF
}

December 17, 2020

\begin{abstract}
The consideration of realistic load assumptions is important for the fatigue design of highly stressed nodular cast iron components for wind energy application. Especially in case of overloads causing elastic-plastic deformation, residual stresses may have a strong impact on fatigue life. In strain-controlled fatigue tests with constant and variable amplitudes, the influence of overloads on the lifetime was investigated. The overload was applied with the objective to create high tensile residual stresses. During fatigue testing the transient material behavior, cyclic hardening, cyclic relaxation of the residual stresses as well as quasi static creep effects, of the EN-GJS-400-18-LT was recorded and evaluated. To quantify the influence of the transient material behavior on the calculated lifetime, fatigue analyses are carried out with the strain-life approach, both with and without consideration of the transient material behavior. The results show that conservative damage sums are derived if the transient material behavior, especially the relaxation of tensile residual stresses, is neglected.
\end{abstract}

\section{Hosted file}

Hesseler2020_FFEMS_V8.pdf available at https://authorea.com/users/383411/articles/499298consideration-of-the-transient-material-behavior-under-variable-amplitude-loading-inthe-fatigue-assessment-of-nodular-cast-iron-using-the-strain-life-approach 